\title{
Foodborne botulism presenting as small bowel obstruction: a case report
}

\author{
Alberto Friziero, Cosimo Sperti ${ }^{*}$, Gianfranco Da Dalt, Nicola Baldan, Gianpietro Zanchettin, Pasquale Auricchio, \\ Laura Gavagna, Andrea Grego, Giulia Capelli and Stefano Merigliano
}

\begin{abstract}
Background: Small bowel obstruction is one of the leading reasons for accessing to the Emergency Department. Food poisoning from Clostridium botulinum has emerged as a very rare potential cause of small bowel obstruction. The relevance of this case report regards the subtle onset of pathognomonic neurological symptoms, which can delay diagnosis and subsequent life-saving treatment.
\end{abstract}

Case presentation: A 24-year-old man came to our Emergency Department complaining of abdominal pain, fever and sporadic self-limiting episodes of diplopia, starting 4 days earlier. Clinical presentation and radiological imaging suggested a case of small bowel obstruction. Non-operative management was adopted, which was followed by worsening of neurological signs. On specifically questioning the patient, we discovered that his parents had experienced similar, but milder symptoms. The patient also recalled eating home-made preserves some days earlier. A clinical diagnosis of foodborne botulism was established and antitoxin was promptly administered with rapid clinical resolution.

Conclusions: Though very rare, botulism can mimic small bowel obstruction, and could be associated with a rapid clinical deterioration if misdiagnosed. An accurate family history, frequent clinical reassessments and involvement of different specialists can guide to identify this unexpected diagnosis.

Keywords: Case report, Botulism, Foodborne botulism, Clostridium botulinum, Small bowel obstruction

\section{Background}

Small bowel obstruction (SBO) is one of the leading reasons for accessing to the Emergency Department with abdominal complaints, accounting for $12-16 \%$ of hospital admissions for acute abdominal pain in the US [1]. The management of this condition depends strongly on its pathogenesis and clinical presentation. According to the Bologna Guidelines for the diagnosis and management of adhesive small bowel obstruction (ASBO), a non-surgical management should be adopted when no clear cause of obstruction is identified, and in the absence of clinical and radiological signs of acute

\footnotetext{
* Correspondence: cosimo.sperti@unipd.it

Department of Surgery, Oncology and Gastroenterology, 3rd Surgical Clinic, University of Padua, via Giustiniani 2, 35128 Padova, Italy
}

conditions requiring emergency surgery (i.e. strangulation, bowel ischemia or peritonitis) [2].

.Food poisoning from Clostridium botulinum has emerged as a very rare potential cause of SBO. In 2017, there were 182 laboratory-confirmed cases of botulism reported to the Atlanta Center for Disease Control, 19 $(10 \%)$ of which were foodborne [3]. In Italy, there were 421 confirmed cases of foodborne botulism between 1986 and 2015 [4]. Its clinical presentation usually includes both gastrointestinal and neurological symptoms, manifesting $12-72 \mathrm{~h}$ after ingestion of the contaminated food [5]. Gastrointestinal symptoms mainly include nausea, vomiting and non-specific, diffuse abdominal pain. Early-onset neurological symptoms include ptosis, disturbed vision, dilated and fixed pupils, dysphagia, dry

(c) The Author(s). 2021 Open Access This article is licensed under a Creative Commons Attribution 4.0 International License, which permits use, sharing, adaptation, distribution and reproduction in any medium or format, as long as you give appropriate credit to the original author(s) and the source, provide a link to the Creative Commons licence, and indicate if changes were made. The images or other third party material in this article are included in the article's Creative Commons licence, unless indicated otherwise in a credit line to the material. If material is not included in the article's Creative Commons licence and your intended use is not permitted by statutory regulation or exceeds the permitted use, you will need to obtain permission directly from the copyright holder. To view a copy of this licence, visit http://creativecommons.org/licenses/by/4.0/ The Creative Commons Public Domain Dedication waiver (http://creativecommons.org/publicdomain/zero/1.0/) applies to the data made available in this article, unless otherwise stated in a credit line to the data. 
mouth and dysphonia, which can progress to a descending symmetrical flaccid paralysis.

Herein we present a clinical case of foodborne botulism presenting with fever and abdominal symptoms of $\mathrm{SBO}$, associated with mild and discontinuous neurological symptoms (lethargy and intermittent diplopia).

We reviewed the English literature, using PubMed (Medline), EMBASE and Scopus, to retrieve previouslyreported cases of botulism initially presenting with clinical and radiological signs of SBO. As keywords we used: "small bowel obstruction", "botulism", and "botulinum". The "related articles" function was used to widen the search, and all abstracts, studies, and citations retrieved were reviewed. We found only one published case, featuring a previously-healthy 45-year-old man, who underwent emergency laparotomy for clinically and radiologically suspected SBO [6].

.This case report is relevant because it shows an unusual clinical presentation of botulism, with a subtle onset of pathognomonic neurological symptoms, which especially in an area in which very few cases have been reported - can delay diagnosis and subsequent lifesaving treatment with antitoxins.

\section{Case presentation}

A 24-year-old man came to our Emergency Department complaining of abdominal pain and fever starting 4 days earlier.

The previously-healthy patient arrived at the Emergency Department with subacute-onset abdominal distension and mildly blurred vision, with intermittent, self-limiting episodes of diplopia. The patient reported no nausea or vomiting, and a regular bowel function.

At initial assessment, the patient was feverish (body temperature $38^{\circ} \mathrm{C}$ ), hemodynamically stable, mildly lethargic, but with no signs of neurological impairment, and he scored 15 on the Glasgow Coma Scale.

Physical examination of the abdomen confirmed mild distension, with rebound tenderness in the right iliac fossa, and a slightly positive Blumberg sign.

Blood tests showed no major alterations other than a high C- reactive protein (CRP) level of $86.3 \mathrm{mg} / \mathrm{L}$ (normal range $0.0-3.0 \mathrm{mg} / \mathrm{L}$ ).

An oropharyngeal swab for the detection of SARSCoV-2 (necessary to allow for further diagnostic and therapeutic procedures) was negative.

Abdominal X-rays showed small bowel distension and the presence of air-fluid levels. (Fig. 1).

A subsequent abdominal computed tomography $(\mathrm{CT})$ scan with intravenous contrast confirmed the small bowel distension with air-fluid levels, and showed a reduction in distal ileum diameter in the right iliac fossa with an empty marbled colon. No obvious causes of mechanical SBO came to light. (Fig. 2).

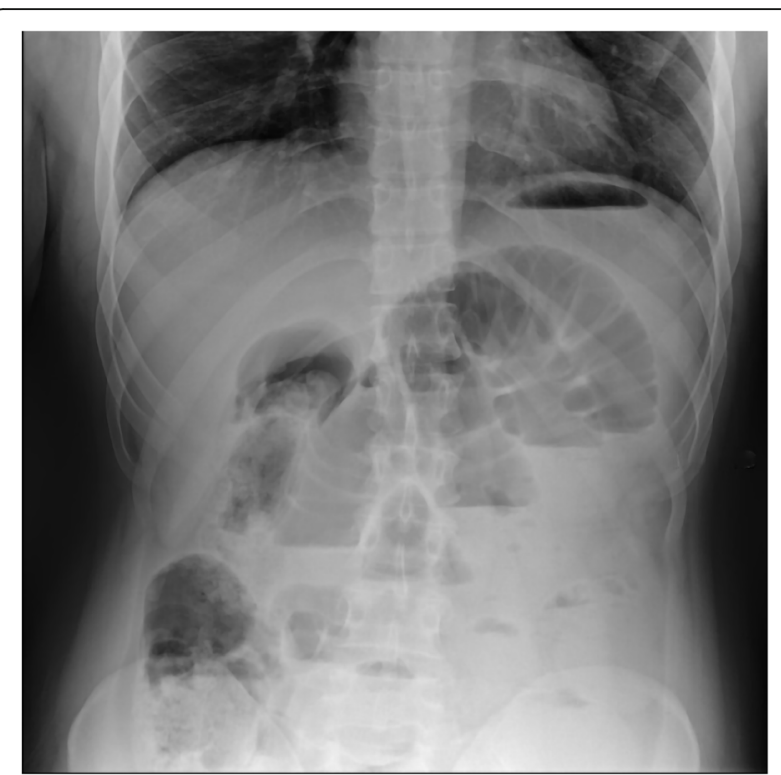

Fig. 1 Abdominal X-rays showing small bowel distension with air-fluid levels

A brain CT scan was also performed to exclude any organic causes of diplopia, and revealed no relevant alterations.

Since no clear cause of mechanic obstruction was identified, and the patient had no signs or symptoms of peritonitis, we opted for a conservative management in accordance with current guidelines [2].

A nasogastric tube was inserted and the patient received nil per os with intravenous supportive therapy. Twenty-four hours after admission, his abdominal pain had improved, and clinical examination showed a painfree, less distended abdomen. Meanwhile, his neurological signs had worsened, with xerostomia, ptosis, mydriasis and diplopia. (Fig. 3a and b) We therefore had

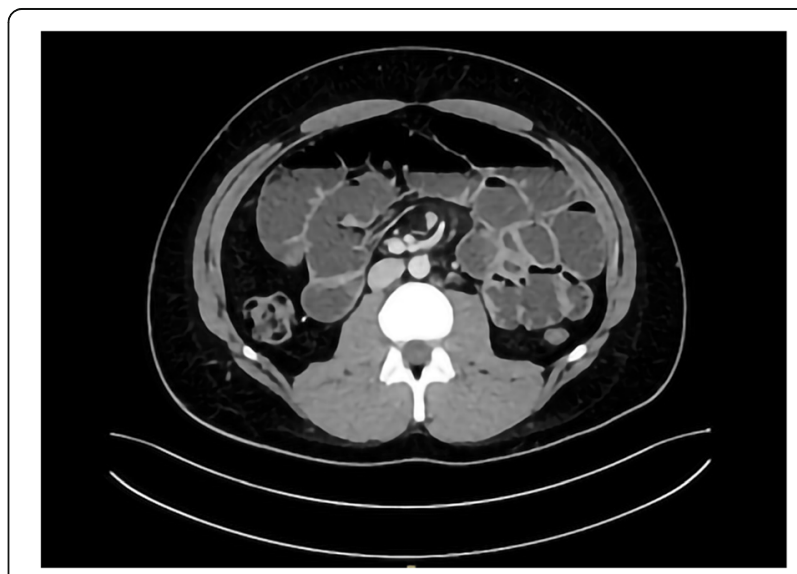

Fig. 2 CT scan with intravenous contrast showing small bowel distension with air-fluid levels, and a reduced distal ileum diameter in the right iliac fossa 

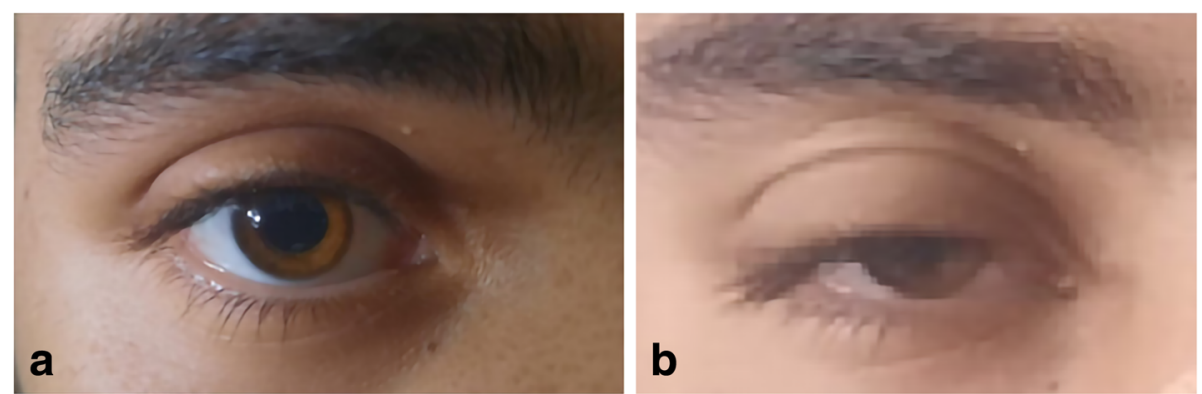

Fig. 3 Neurological signs. a Mydriasis. b Ptosis

the patient assessed by our consultant neurologist. Both heavy metal and food poisoning were considered in the differential diagnosis. On specifically questioning the patient, we discovered that his parents had experienced similar, but milder symptoms, such as dizziness, xerostomia, nausea and non-specific, diffuse abdominal pain; anyhow, no signs of SBO were present in the patient's parents. The patient also recalled eating home-made preserves 6 days earlier. After consulting our Poison Control Center, i.e. the Centro Antiveleni (CAV) e Centro Nazionale di Informazione Tossicologica (C.N.I.T.) of Pavia, a clinical diagnosis of foodborne botulism poisoning due to home-made preserves was formulated. The clinical suspicion was confirmed by multiplex realtime polymerase chain reaction (CNRB31.0112019 Rev.1) assay [7], performed at the Istituto Superiore di Sanità (ISS), Dipartimento di Sicurezza Alimentare, Nutrizione e Sanità Pubblica Veterinaria, to which all suspected botulism cases are referred for laboratory confirmation. Five consecutive rectal swabs were positive for Clostridium botulinum type $B$.

We consequently started treatment with Botulism Antitoxin Heptavalent (BAT ${ }^{\circ}$ ), obtaining a near-total resolution of the patient's symptoms within about $24 \mathrm{~h}$.

The patient's parents also tested positive for Clostridium botulinum type $B$, with the same diagnostic modalities mentioned above, and were treated accordingly, obtaining immediate clinical benefit.

\section{Discussion and conclusions}

SBO is one of the leading causes of hospital admissions for surgery, and one of the most common emergencies requiring surgical treatment [8]. Although postoperative or post-infectious adhesions are responsible for most cases of SBO, no mechanical cause of the obstruction can be identified in about $11 \%$ of cases [9]. This possibility should not be underestimated especially in emergency surgery units, where large numbers of cases of SBO are treated every year. In this setting, even unusual or rare diseases should be included in the differential diagnosis of SBO with no apparent mechanical cause.
To date, six forms of botulism are recognized and classified according to the modality of exposure to the toxin [4].

.The last relevant outbreak of food borne botulism in Italy dates back to 1996 [10]. Nevertheless, such a possible diagnosis should not be neglected when faced with patients presenting acute gastrointestinal complaints associated with even mild neurological symptoms.

Only one case had previously been reported in the English literature: Authors described performing an emergency exploratory laparotomy in a patient presenting with $\mathrm{SBO}$, who was subsequently diagnosed with botulism. No data were available concerning the patient's postoperative recovery, or the effects of general anesthesia and curarization in particular [6].

.As concerns other forms of botulism, it is acknowledged that intestinal botulism (due to intestinal colonization by neurotoxigenic clostridia) can mimic a surgical emergency [11]. Three cases have been reported of intestinal botulism in adult patients presenting with acute abdominal symptoms [12]. Two of them underwent surgery for clinically-suspected acute appendicitis, and both experienced worsening neurological symptoms after surgery, subsequently requiring intensive care with mechanical ventilation. The third patient was admitted for neurological symptoms (i.e. diplopia and dysphagia), nausea and vomiting, and was treated conservatively, with a more favorable outcome. It is therefore reasonable to believe that the unnecessary surgical treatment of misdiagnosed botulism could be associated with a higher rate of postoperative complications, including the need for mechanical ventilation.

In our case, frequent clinical reassessments provided the key to identifying new, more relevant symptoms pointing to an unexpected diagnosis. The involvement of consultants from different specialties also contributed to improve the patient's final outcome. It is worth noting that the patient's family history provided an important clue to the diagnosis; the significance of this aspect when collecting a patient's history should never be underestimated. 
In conclusion, it is important to acknowledge that the extensive use of standardized protocols for managing the most common surgical emergencies can sometimes be misleading when we are dealing with an uncommon diagnosis. Though very rare, botulism has the potential to cause $\mathrm{SBO}$, and could be associated with a rapid clinical deterioration if it goes misdiagnosed. Conducting frequent clinical reassessments, involving specialists from different fields, and paying careful attention to the possibility of less common diagnoses could be the key to a patient's positive outcome.

\section{Abbreviations}

SBO: Small bowel obstruction; ASBO: Adhesive small bowel obstruction; CRP: C-reactive protein; CT: Computed tomography; SARS-CoV-2: Severe acute respiratory syndrome coronavirus 2

\section{Acknowledgements}

We thank the Centro Antiveleni (CAV) e Centro Nazionale di Informazione Tossicologica (C.N.I.T.) of Pavia, Pavia, Italy, and the the Istituto Superiore di Sanità (ISS), Dipartimento di Sicurezza Alimentare, Nutrizione e Sanità

Pubblica Veterinaria, for the clinical and diagnostic support.

\section{Authors' contributions}

AF, GC and PA conceived the study, conducted the literature search, and drafted the manuscript; GDD, NB, GZ, AG and LG helped with patient management; CS and SM supervised the study and critically revised the paper. All authors read and approved the final manuscript.

\section{Funding}

No funding

\section{Availability of data and materials}

Not applicable.

Ethics approval and consent to participate

Not applicable.

\section{Consent for publication}

Written informed consent for publication of their clinical details and clinical images was obtained from the patient. A copy of the consent form is available for review by the Editor of this journal.

\section{Competing interests}

The authors declare that they have no competing interests.

Received: 3 November 2020 Accepted: 30 December 2020

Published online: 12 January 2021

\section{References}

1. Nicolaou S, Kai B, Ho S, Su J, Ahamed K. Imaging of acute small-bowel obstruction. AJR Am J Roentgenol. 2005;185(4):1036-44.

2. Ten Broek RPG, Krielen P, Di Saverio S, Coccolini F, Biffl WL, Ansaloni L, et al. Bologna quidelines for diagnosis and management of adhesive small bowel obstruction (ASBO): 2017 update of the evidence-based guidelines from the world Society of Emergency Surgery ASBO working group. World J Emerg Surg. 2018;13:24

3. National Botulism Surveillance Summary, 2017. https:/www.cdc.gov/ botulism/surv/2017/index.html. Accessed 01 Sep 2020.

4. Anniballi F, Auricchio B, Fiore A, et al. Botulism in Italy, 1986 to 2015. Euro Surveill. 2017:22(24):30550.

5. Jeffery LA, Karim S. Botulism. In: StatPearls [internet]. Treasure Island: StatPearls Publishing; 2020. Available from: https://www.ncbi.nlm.nih.gov/ books/NBK459273. Accessed 01 Sep 2020.

6. Spiegelman J, Cescon DW, Friedman Y, Mazza BV, Austin JW, Rachlis A, et al. Bowel loops and eyelid droops. CMAJ. 2008;179(9):927-9.
7. Centro Nazionale di Riferimento per il Botulismo. Metodi di analisi. https:// www.iss.it/documents/20126/0/CNRB30.011.pdf/59a7faf1-15f5-dd54-ae13d066de9dcea2? $t=1582362668086$. Accessed 16 Dec 2020.

8. NELA Project Team. The second patient report of the National Emergency Laparotomy Audit (NELA). London: The Royal College of Anaesthetists; 2016. https://www.nela.org.uk/downloads/The\%20Second\%20Patient\%2 OReport\%20of\%20the\%20National\%20Emergency\%20Laparotomy\%2 OAudit\%202016\%20-\%20Executive\%20Summary.pdf. Accessed 01 September 2020.

9. Miller G, Boman J, Shrier I, Gordon PH. Etiology of small bowel obstruction. Am J Surg. 2000;180(1):33-6.

10. Aureli P, Franciosa G, Pourshaban M. Foodborne botulism in Italy. Lancet. 1996;348(9041):1594.

11. Harris RA, Anniballi F, Austin JW. Adult intestinal toxemia botulism. Toxins (Basel). 2020;12(2):81.

12. Fenicia L, Anniballi F, Aureli P. Intestinal toxemia botulism in Italy, 19842005. Eur J Clin Microbiol Infect Dis. 2007:26(6):385-94

\section{Publisher's Note}

Springer Nature remains neutral with regard to jurisdictional claims in published maps and institutional affiliations.

Ready to submit your research? Choose BMC and benefit from:

- fast, convenient online submission

- thorough peer review by experienced researchers in your field

- rapid publication on acceptance

- support for research data, including large and complex data types

- gold Open Access which fosters wider collaboration and increased citations

- maximum visibility for your research: over $100 \mathrm{M}$ website views per year

At BMC, research is always in progress.

Learn more biomedcentral.com/submissions 